\title{
Influence of Fertilization Systems on Physical and Chemical Properties of the Soil
}

\author{
OANA MARIA MUSCALU (PLESCAN) ${ }^{1,2}$, VALENTIN NEDEFF 1,3 , ALEXANDRA DANA CHITIMUS ${ }^{1 *}$, IOAN GABRIEL SANDU ${ }^{4,5}$, \\ ELENA PARTAL ${ }^{6}$, EMILIAN MOSNEGUTU ${ }^{1}$, ION SANDU ${ }^{5,7 *}$, DRAGOS IOAN RUSU ${ }^{1}$ \\ ${ }^{1}$ Vasile Alecsandri University of Bacau, Department of Environmental Engineering and Mechanical Engineering, 157 Calea \\ Marasesti, 600115, Bacau , Romania \\ ${ }^{2}$ Romanian Waters - National Administration of Siret Basin, 1 Cuza Voda Str., 600274, Bacau, Romania \\ ${ }^{3}$ Gheorghe Ionescu Sisesti, Academy of Agricultural and Forestry Sciences Bucharest, 61 Marasti Blvd., 011464, Bucharest, \\ Romania \\ ${ }^{4}$ Gheorghe Asachi Technical University of Iasi, Faculty of Material Sciences and Engineering, 69 Dumitru Mangeron Str., 700050, \\ lasi, Romania \\ ${ }^{5}$ Romanian Inventors Forum, 3 Sf. Petru Movila St., BI. L11, III/3, 700089, Iasi, Romania \\ ${ }^{6}$ National Agricultural Research and Development Institute of Fundulea, Calarasi, 1 Nicolae Titulescu Str., 915200, Fundulea, \\ Romania \\ ${ }^{7}$ Alexandru Ioan Cuza University of lasi, ARHEOINVEST Interdisciplinary Platform, 22 Carol I Blvd., 700506, Iasi, Romania
}

\begin{abstract}
The purpose of this research have been to determine the influence of soil fertilizations systems (fertilization with: nitrogen, phosphorous, nitrogen and phosphorous, farmyard manure) on the physical properties (penetration hardness) and chemical properties (humidity, metals) of the soil. The experiments have been carried out in the experimental field of National Agricultural Research and Development Institute -Fundulea, Romania, for a wheat monoculture. The lowest values of the metal content in soil (nickel, copper, zinc, arsenic, lead) have been recorded for wheat experimental variant -fertilized with N90P75 kg/ha ( $\left.a_{1} b_{4}\right)$, and the highest content have been recorded for manganese ( $766 \mathrm{mg} / \mathrm{kg}$ dry matter), and for the wheat experimental variant $a_{1} b_{4}$, respectively (wheat-fertilized with N90P75 kg/ha active matter), working depth $0-15 \mathrm{~cm}$.
\end{abstract}

Keywords: nitrogen, phosphorus, farmyard manure, wheat, monoculture

Natural (organic) fertilizers are a source of nutritive mineral elements for plants, thus contributing to the improvement of physical and biological features of the soil. Farmyard manure has a complex effect on plants and soil. It is applied in summer and autumn and it is embedded in soil by ploughing. Higher doses are recommended for low fertility soils and on irrigated surfaces, for intensive culture [1-10].

Plant growth and development processes require large quantities of nutritive elements, extracted from soil through the roots. Consumption balance is possible by applying fertilizers, avoiding the lowering of soil's productive potential [11-26].

The purpose of this research has been to determine the influence of soil fertilizations systems on the physical properties (penetration hardness) and chemical properties (humidity, metals: chrome, manganese, nickel, copper, zinc, arsenic, lead, cadmium).

\section{Experimental part}

When choosing the sampling point in order to determine the heavy metal content and physical properties of the soil, the research team took into account the topo-pedological base of the agrochemical cropping plots, updated with all necessary elements to identify and locate the plots.

The study has been carried out in the experimental field of National Agricultural Research and Development Institute- Fundulea, Romania, for a wheat monoculture. The researches at INCDA have been carried out following a two-factor experience, stationary and multiannual, mounted in 1968 and up to date, with reference to emphasizing the differentiation of soil's properties as an effect of fertilization sequence, i.e:

- nitrogen (90 kg N/ha active matter - active matter);
- phosphorous ( $75 \mathrm{~kg} \mathrm{P} / \mathrm{ha}$ active matter); - nitrogen and phosphorous (N90P75 kg/ha active matter):

- farmyard manure.

The experimental variants carried out at INCDA have been of the following type (fig. 1, table 1):

- wheat monoculture (Factor $a): a_{1}$.

- fertilization with (Factor b):

-unfertilized: $b_{1}$ (NOPO kg/ha active matter); -nitrogen - $90 \mathrm{~kg} \mathrm{~N} / \mathrm{ha}$ active matter: $b_{2}$;

-phosphorous - $75 \mathrm{~kg}$ P/ha active matter: $b_{3}$; -nitrogen and phosphorous - N90P75 kg/ha active matter: $b_{i}$;

-farmyard manure: $b_{5}$.

\begin{tabular}{|c|c|}
\hline YEAR & FACTOR \\
\cline { 2 - 2 } & al \\
\hline $2006 \div 2016$ & wheat \\
\hline
\end{tabular}

Table 1

SOIL CROP-ROTATION FOR THE PERIOD 2006-2016, I.E. FOR WHEAT CULTURE

The soil samples have been taken on two depths: - 0 - $15 \mathrm{~cm}$;

- $15-30 \mathrm{~cm}$.

Fig. 1. Experimental variant by INCDA

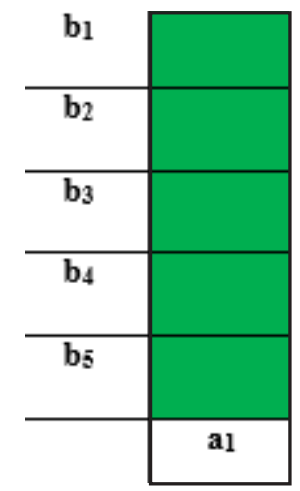


Soil samples

Drying at room temperature.

2. Screening the samples to obtain particles. The

soil is screened to a fraction smaller than $2 \mathrm{~mm}$.

3. Mineralization of soil samples in aqua regia.
Fig. 2. Soil samples preparation methods to determine heavy metals through inductively coupled plasma mass spectrometry, and atomic absorption spectrometry respectively [27-30].
The soil samples have been taken in 2016. All soil samples have been collected as a composite form each parcel after wheat harvesting.

Figure 2 shows soil sampling method used to determine the soil heavy metal content.

Moreover, in the filed have been determined: 3);

- soil penetration hardness, by the penetrologger (fig.

- soil humidity, by the in situ direct reading moisture sensor (fig. 4).

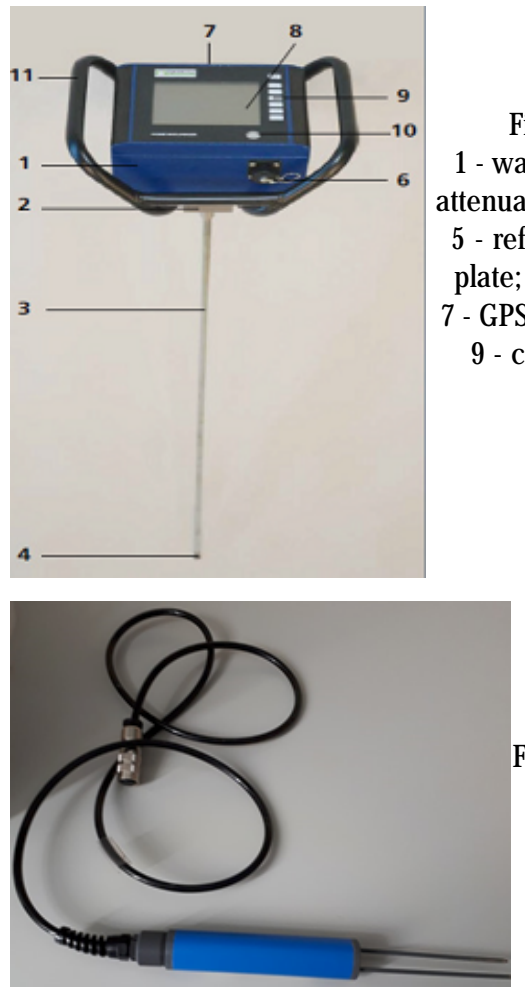

Fig. 3. Penetrologger: 1 - waterproof case; 2 - impact attenuator; 3 - draw bar; 4 - cone; 5 - reference depth measuring plate; 6 - communication port; - GPS antenna; 8 - LCD screen; 9 - control panel; 10 - level; 11 - handgrips [30]

Fig. 4. Moisture sensor [30]

Experiments have been carried out for the content of eight metals in the soil: chrome, manganese, nickel, copper, arsenic, lead, cadmium.

The metal content in the soil samples has been determined by using inductively coupled plasma mass spectrometer (ICP-MS) [17], Agilent 7500cx ICP-MS version and an atomic absorption spectrometer (AAS), ZEENIT AAS version. Through the inductively coupled plasma mass spectrometry, the following metals have been detected: chrome, nickel, copper, arsenic, lead, and cadmium. Through atomic absorption spectrometry, zinc and manganese content has been detected [28, 29].

\section{Results and discussions}

Tables 2 and 3 show the experimentally determined values for the soil samples taken on the unfertilized wheat parcel (control sample) for eight heavy metal and for the in physical properties measured in situ.

Table 3 shows the experimentally determined values for eight metals in soil in which a wheat monoculture has been embedded, with fertilization sequence in 2016.

The manganese content value (fig. 5) registered in the nitrogen fertilized parcel (90 kg N/ha) was $9.02 \%$ lower than the value registered in the unfertilized soil parcel for the $0-15 \mathrm{~cm}$ depth, respectively by $14.79 \%$ lower than the control sample for the $15-30 \mathrm{~cm}$ depth.

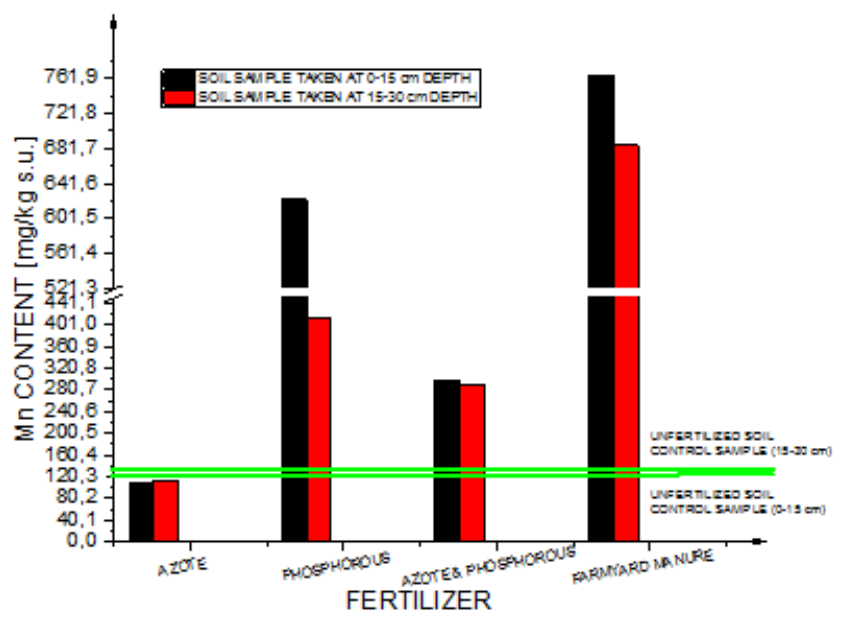

Fig. 5. Manganese content in soil parcels fertilized with nitrogen, phosphorous, nitrogen and phosphorous, farmyard manure, for the $0-15 \mathrm{~cm}$ and $15-30 \mathrm{~cm}$ depths respectively

\begin{tabular}{|c|c|c|c|c|c|c|c|c|}
\hline \multirow{2}{*}{$\begin{array}{c}\text { Depth } \\
\text { [cm] }\end{array}$} & $\mathbf{C r}$ & $\mathbf{M n}$ & $\mathbf{N i}$ & $\mathbf{C u}$ & $\mathbf{Z n}$ & As & Pb & Cd \\
\cline { 2 - 9 } & \multicolumn{7}{|c|}{ [mg/kg s.u.] } \\
\hline $0-15$ & LOQ* & 120.30 & 25.44 & 14.36 & 19.65 & 7.79 & 13.95 & 0.13 \\
\hline $15-30$ & LOQ* & 133.90 & 36.33 & 22.15 & 50.55 & 10.63 & 18.15 & 0.29 \\
\hline
\end{tabular}

* Values below the Limit of Quantitation (LOQ) of the method.

\begin{tabular}{|c|c|c|}
\hline $\begin{array}{c}\text { Depth } \\
{[\mathrm{cm}]}\end{array}$ & $\begin{array}{c}\text { Humidity } \\
{[\%]}\end{array}$ & Resistance to penetration [MPa] \\
\hline $0-15$ & 4 & 3.00 \\
\hline $15-30$ & 7 & 2.70 \\
\hline
\end{tabular}

http://www.revistadechimie.ro
Table 2

EXPERIMENTALLY DETERMINED VALUES FOR THE EIGHT METALS IN THE UNFERTILIZED SOIL PARCEL (CONTROL SAMPLE)
Table 3

EXPERIMENTALLY DETERMINED VALUES FOR HUMIDITY AND RESISTANCE TO PENETRATION HARDNESS IN THE UNFERTILIZED SOIL PARCEL (CONTROL SAMPLE) 
In the case of the phosphorous fertilized parcel $(75 \mathrm{~kg}$ $\mathrm{P} / \mathrm{ha}$ ) the soil manganese content was $517.87 \%$ higher than the value registered on the unfertilized soil parcel for the $0-15 \mathrm{~cm}$ depth, respectively $309.55 \%$ higher for the 15 $30 \mathrm{~cm}$ depth;

The nickel content value (fig. 6) on the nitrogen fertilized parcel was $112.22 \%$ higher than the control sample value for the $0-15 \mathrm{~cm}$ depth. For the $15-30 \mathrm{~cm}$ depth the nickel content was $77.73 \%$ of the control sample value.

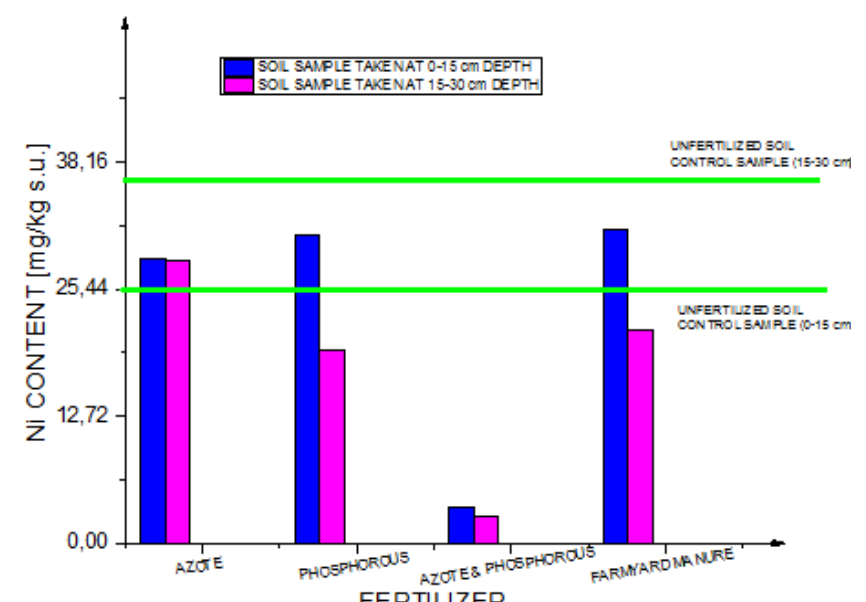

Fig. 6. Nickel content on soil parcels fertilized with nitrogen, phosphorous, nitrogen and phosphorous, farmyard manure for the $0-15 \mathrm{~cm}$ and $15-30 \mathrm{~cm}$ depths

For the soil parcel fertilized with $75 \mathrm{~kg} P / \mathrm{ha}\left(b_{3}\right)$ factor, the nickel content was $121.14 \%$ higher than the control sample value, for the $0-15 \mathrm{~cm}$ depth, respectively $46.62 \%$ lower than the control sample value for the $15-30 \mathrm{~cm}$ depth.

The nickel content for the experimental wheat variants -fertilized with nitrogen and phosphorous N90P75 kg/ha $\left(a_{1} b_{4)}\right.$ and wheat-fertilized with farmyard manure $\left(a_{1} b_{5}\right)$ wàs:

- wheat - fertilization with nitrogen and phosphorous N90P $75 \mathrm{~kg} / \mathrm{ha}\left(\mathrm{a}_{1} \mathrm{~b}_{4}\right.$ :

ï\% $0-15 \mathrm{~cm}: 14.46 \%$ of the soil control sample value;

$1 \% 15-30 \mathrm{~cm}: 7.37 \%$ of the soil control sample value;

- wheat- fertilization with farmyard manure $\left(a_{1} b_{5}\right)$ :

i\% 0-15 cm: $123.11 \%$ lower than the valued registered in the soil sample with no fertilization sequence;

$1 \% 15-30 \mathrm{~cm}: 41.34 \%$ lower than the valued registered in the soil sample with no fertilization sequence.

The copper content value (fig. 7) registered for the soil parcel fertilized with nitrogen was $109.22 \%$ higher than the value registered for the unfertilized soil parcel for the 0 $15 \mathrm{~cm}$ depth, respectively $30.79 \%$ lower than the control sample, for the $15-30 \mathrm{~cm}$ depth.

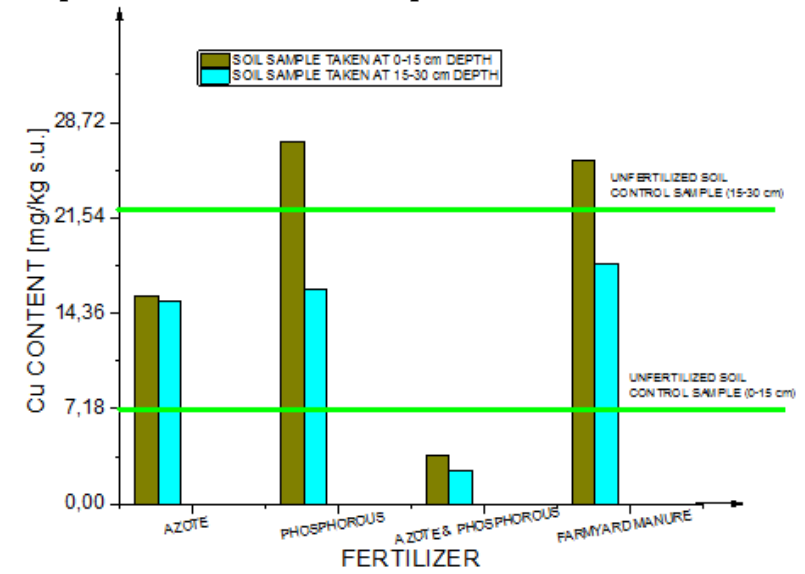

Fig. 7. Copper content on soil parcels fertilized with nitrogen, phosphorous, nitrogen and phosphorous, farmyard manure for the $0-15 \mathrm{~cm}$ and $15-30 \mathrm{~cm}$ depths
In the case of the phosphorous fertilized parcel, the copper content was $190.18 \%$ higher than the value registered for the unfertilized soil parcel for the $0-15 \mathrm{~cm}$ depth, respectively $27.31 \%$ lower than the control sample, for the $15-30 \mathrm{~cm}$ depth.

The coppercontent for the experimental wheat variants -fertilized with nitrogen and phosphorous N90P75 kg/ha $\left(a_{1} b_{4}\right)$ was:

- $0-15 \mathrm{~cm}: 25.833 \%$ of the soil control sample value; - $15-30 \mathrm{~cm}: 11.33 \%$ of the soil control sample value.

For the soil parcel fertilized with farmyard manure $\left(b_{5}\right)$ the copper content was $180.36 \%$ higher than the control sample value, for the $0-15 \mathrm{~cm}$ depth, respectively $18.64 \%$ lower than the control sample, for the $15-30 \mathrm{~cm}$ depth.

Zinc content (fig. 8) for the analysed experimental variants was:

- wheat - fertilization with nitrogen - $90 \mathrm{~kg} \mathrm{~N} / \mathrm{ha}\left(a_{1} b_{2}\right)$ :

ï\% 0-15 cm: $114.24 \%$ higher than the valued registered in the soil sample with no fertilization sequence;

i\% 15-30 cm: $36.69 \%$ of the soil control sample value;

- wheat - fertilization with phosphorous $-75 \mathrm{~kg} \mathrm{P/ha}$ $\left(a_{1} b_{2}\right)$ :

$1 \%$ 0-15 cm: cu $232.41 \%$ higher than the valued registered in the soil sample with no fertilization sequence;

1\% 15-30 cm: cu 46.27\% lower than the valued registered in the soil sample with no fertilization sequence. - wheat - fertilization with nitrogen and phosphorous N90P75 kg/ha $\left(a_{1} b_{1}\right)$ :

1\% $0-15 \mathrm{~cm}: 17.4 \%$ of the soil control sample value;

i $\% 15-30 \mathrm{~cm}: 6.76 \%$ of the soil control sample value;

- wheat-fertilization with farmyard manure $\left(a_{1} b_{5}\right)$ :

I\% 0-15 cm: cu $236.74 \%$ higher than the valued registered in the soil sample with no fertilization sequence;

$1 \%$ 15-30 cm: cu $35.98 \%$ lower than the valued registered in the soil sample with no fertilization sequence.

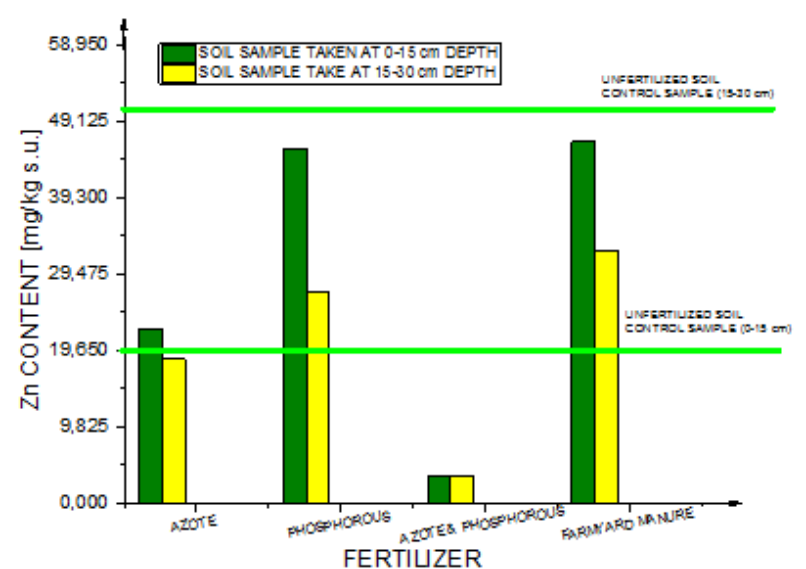

Fig. 8. Zinc content on soil parcels fertilized with nitrogen, phosphorous, nitrogen and phosphorous, farmyard manure for the $0-15 \mathrm{~cm}$ and $15-30 \mathrm{~cm}$ depths

Arsenic content value (fig. 9) registered for the soil parcel fertilized with nitrogen was $129.65 \%$ higher than the control sample value for the $0-15 \mathrm{~cm}$ depth. For the $15-30 \mathrm{~cm}$ depth the nickel content was $83.63 \%$ of the control sample value.

For the soil parcel fertilized with phosphorous $\left(b_{3}\right)$, the arsenic content was $125.93 \%$ higher than the control sample value for the $0-15 \mathrm{~cm}$ depth, respectively $32.07 \%$ lower than the control sample, for the $15-30 \mathrm{~cm}$ depth.

The arsenic content for the experimental variants wheat -fertilization with nitrogen, and phosphorous N90P75 kg/ ha $\left(a_{1} b_{4}\right)$ and wheat- fertilization with farmyard manure $\left(a_{1} b_{5}\right)^{1}$ was: 


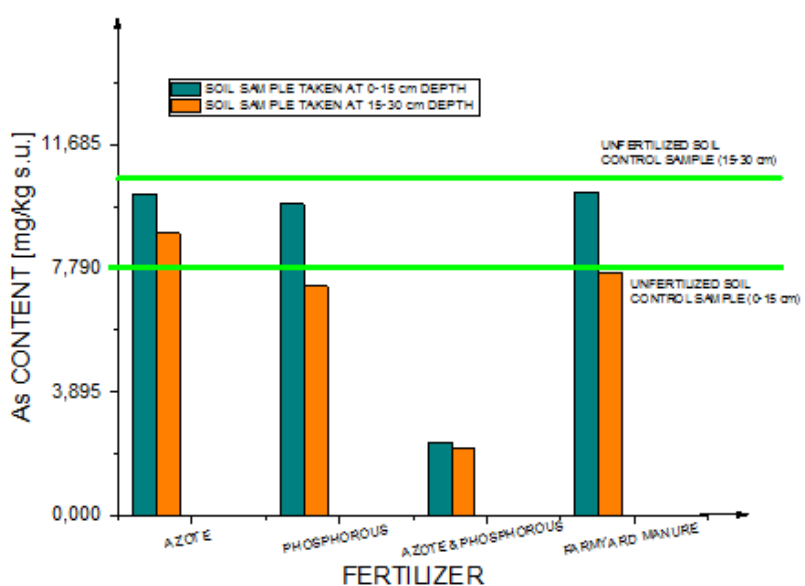

Fig. 9. Arsenic content on soil parcels fertilized with nitrogen, phosphorous, nitrogen and phosphorous, farmyard manure for the $0-15 \mathrm{~cm}$ and $15-30 \mathrm{~cm}$ depths

- wheat- fertilization with nitrogen and phosphorous N90P75 kg/ha $\left(a_{1} b_{1}\right)$ :

$1 \% 0-15 \mathrm{~cm}: 29.78 \%$ of the soil control sample value;

i\% $15-30 \mathrm{~cm}: 19.94 \%$ of the soil control sample value; - wheat- fertilization with farmyard manure $\left(a_{1} b_{5}\right)$ :

i\% 0-15 cm: $129.65 \%$ higher than the valued registered in the soil sample with no fertilization sequence;

1\% 15-30 cm: cu $27.93 \%$ lower than the valued registered in the soil sample with no fertilization sequence.

The lead content (fig. 10) registered for the soil parcel fertilized with nitrogen was (90 kg N/ha) was $116.34 \%$ higher than the value registered for the unfertilized soil parcel for the $0-15 \mathrm{~cm}$ depth, respectively $151.73 \%$ higher than the control samble. for the $15-30 \mathrm{~cm}$ denth.

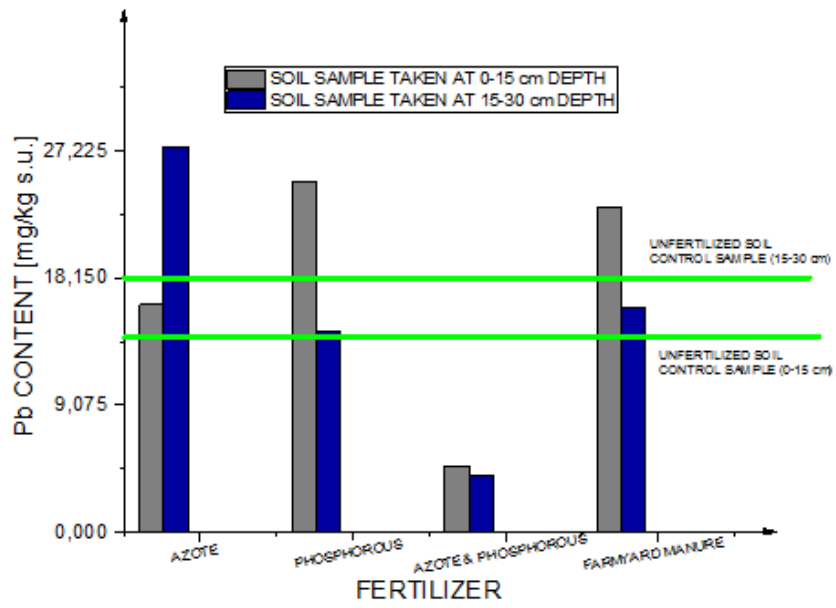

Fig. 10. Lead content on soil parcels fertilized with nitrogen, phosphorous, nitrogen and phosphorous, farmyard manure for the $0-15 \mathrm{~cm}$ and $15-30 \mathrm{~cm}$ depths

In the case of the soil parcel fertilized with phosphorous ( $75 \mathrm{~kg}$ P/ha) the soil lead content was $179.21 \%$ higher than the value registered for the unfertilized soil parcel for

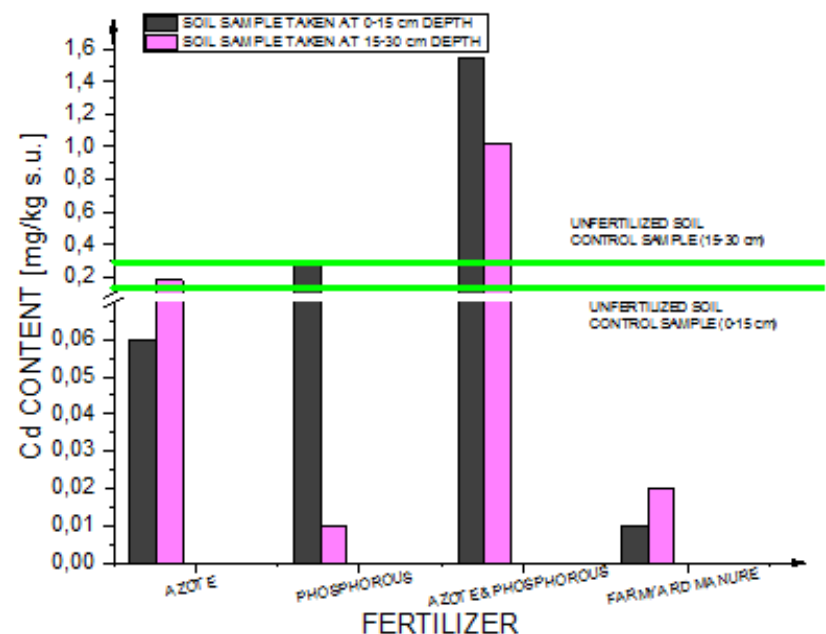

Fig. 11. Cadmium content on soil parcels fertilized with nitrogen, phosphorous, nitrogen and phosphorous, farmyard manure for the $0-15 \mathrm{~cm}$ and $15-30 \mathrm{~cm}$ depths.

the $0-15 \mathrm{~cm}$ depth, respectively $21.15 \%$ lower than the control sample, for the $15-30 \mathrm{~cm}$ depth.

For the soil parcel fertilized with nitrogen and phosphorous $\left(b_{4}\right)$, the lead content was $33.62 \%$ of the soil control sample value, for the $0-15 \mathrm{~cm}$ depth, respectively $22.14 \%$ of the soil control sample value for the $15-30 \mathrm{~cm}$ depth.

For the soil parcel fertilized with farmyard manure $\left(b_{5}\right)$, the lead content was $166.52 \%$ higher than the value registered for in the soil control sample, for the $0-15 \mathrm{~cm}$ depth, respectively $11.95 \%$ lower than the value registered for in the soil control sample, for the15-30 cm depth.

Cadmium content (fig. 11) for the analysed experimental variants was:

- wheat- fertilization with nitrogen - $90 \mathrm{~kg} \mathrm{~N} / \mathrm{ha}\left(a_{1} b_{2}\right)$ :

ï $0-15 \mathrm{~cm}: 46.15 \%$ of the soil control sample value;

$1 \%$ 15-30 cm: $62.06 \%$ of the soil control sample value;

- wheat- fertilization with phosphorous $-75 \mathrm{~kg} P / \mathrm{ha}$ $\left(a_{1} b_{0}\right)$ :

$1 \%$ 0 $-15 \mathrm{~cm}: 223.07 \%$ higher than the valued registered in the soil sample with no fertilization sequence;

1\% 15-30 cm: $96.55 \%$ lower than the valued registered in the soil sample with no fertilization sequence.

- wheat - fertilization with nitrogen and phosphorous N90P75 kg/ha $\left(a_{1} b_{1}\right)$ :

$1 \% 0-15 \mathrm{~cm}: 1184.61 \%$ higher than the valued registered in the soil sample with no fertilization sequence;

I\% 15-30 cm: 351.72\% higher than the valued registered in the soil sample with no fertilization sequence;

- wheat- fertilization with farmyard manure $\left(a_{1} b_{5}\right)$ :

i\% 0-15 cm: $7.69 \%$ of the soil control sample value;

i\% $15-30 \mathrm{~cm}: 6.89 \%$ of the soil control sample value.

In the case of the chrome, the values registered for each fertilization sequence have been below the Limit of Quantitation.

\begin{tabular}{|c|c|c|c|}
\hline Experimental value & $\begin{array}{c}\text { Depth } \\
{[\mathbf{c m}]}\end{array}$ & $\begin{array}{c}\text { Humidity } \\
{[\%]}\end{array}$ & $\begin{array}{c}\text { Resistence to } \\
\text { penetration } \\
{[\mathbf{M P a}]}\end{array}$ \\
\hline \multirow{2}{*}{$\mathbf{a}_{1} \mathbf{b}_{\mathbf{2}}$} & $0-15$ & 5 & 3.70 \\
\cline { 2 - 4 } & $15-30$ & 5 & 2.80 \\
\hline \multirow{2}{*}{$\mathbf{a}_{1} \mathbf{b}_{3}$} & $0-15$ & 3 & 3.60 \\
\cline { 2 - 4 } & $15-30$ & 8 & 3.10 \\
\hline \multirow{2}{*}{$\mathbf{a}_{1} \mathbf{b}_{4}$} & $0-15$ & 3 & 2.90 \\
\cline { 2 - 4 } & $15-30$ & 8 & 3.10 \\
\hline \multirow{2}{*}{$\mathbf{a}_{1} \mathbf{b}_{5}$} & $0-15$ & 2 & 2.70 \\
\cline { 2 - 4 } & $15-30$ & 9 & 2.80 \\
\hline
\end{tabular}

Table 4

EXPERIMENTALLY DETERMINED VALUES FOR HUMIDITY AND RESISTENCE TO PENETRATION FOR SOIL PARCELS WHERE A FERTILIZATION SEQUENCE HAS BEEN APPLIED 
Soil humidity has been registered with values between 2 and $9 \%$

Soil humidity value (table 4) for the soil parcel where a fertilization sequence has been applied was $125 \%$ higher than the value registered on unfertilized soil parcel for the $0-15 \mathrm{~cm}$ depth.

For the $15-30 \mathrm{~cm}$ working depth, the soil humidity lowered by $28.57 \%$ compared to the soil control sample.

For the experimental wheat variants - fertilization with phosphorous - $75 \mathrm{~kg}$ P/ha $\left(a_{1} b_{3}\right)$ and wheat - fertilization with nitrogen and phosphorous - N90P75 kg/ha $\left(a_{1} b_{4}\right)$, soil humidity for the $10-15 \mathrm{~cm}$ w orking depth was $25 \%$ lower than the soil control sample, and for the $15-30 \mathrm{~cm}$ depth it was $114.28 \%$ higher than the soil control sample.

The lowest humidity value (compared to all the other experimental variants) has been registered for the experimental variant wheat - fertilization with farmyard manure $\left(a_{1} b_{5}\right)$, for the $0-15 \mathrm{~cm}$ working depths, respectively $50 \%$ of the soil control sample value.

In the case of the experimental variant wheat fertilization with farmyard manure $\left(a_{1} b_{5}\right), 15-30 \mathrm{~cm}$ depth, the highest humidity value has been registered, compared to all the other experimental variants (128. $57 \%$ higher than the control sample value.)

Resistance to penetration values varied between 2.70 $\div 3.70 \mathrm{MPa}$, meaning that the soil is in the light soil category.

Soil's resistance to penetration (table 4) for the analysed experimental variants was:

- wheat- fertilization with nitrogen - 90kg N/ha $\left(a_{1} b_{2}\right)$ :

ï\% 0-15 cm: $123.33 \%$ higher than the valued registered in the soil sample with no fertilization sequence;

i\% 15-30 cm: 103.7\% higher than the valued registered in the soil sample with no fertilization sequence;

- wheat- fertilization with phosphorous $-75 \mathrm{~kg} P / \mathrm{ha}$ $\left(a_{1} b_{3}\right)$ :

$10 \% 0-15 \mathrm{~cm}: 120 \%$ higher than the valued registered in the soil sample with no fertilization sequence;

i\% 15-30 cm: 114.81\% higher than the valued registered in the soil sample with no fertilization sequence.

- wheat - fertilization with nitrogen and phosphorous N90P75 kg/ha $\left(a_{1} b_{4}\right)$

ï 0-15 cm: $3.33 \%$ lower than the valued registered in the soil sample with no fertilization sequence;

i\% $15-30 \mathrm{~cm}$ : $114.81 \%$;

- wheat- fertilization with farmyard manure $\left(a_{1} b_{5}\right)$ :

ï\% $0-15 \mathrm{~cm}: 90 \%$ of the higher than the valued registered in the soil sample with no fertilization sequence soil control sample value;

I\% 15-30 cm: 103.7 \% higher than the valued registered in the soil sample with no fertilization sequence.

The extremely high values of the soil's manganese content are due to its high capacity of metal stabilization by the Triticum aestivum species (wheat) through the phyto-stabilization process.

The lowest metal content values have been registered for the fertilization with nitrogen and phosphorous $\left(b_{4}\right)$, for the $15-30 \mathrm{~cm}$ working depth, except for the cadmium, where the registered value was much higher than the control sample.

\section{Conclusions}

Modern, intensive, high-yielding farming exerts a considerable stress on soil. The numerous crops, diversification of cultures, with or without taking into account the crop-rotation, severe modification of aerohydric regime through irrigation and drainage, increment of ploughing depth, intense traffic very often with high heavy vehicles, fertilization and other technological measures, strictly necessary to obtain a high productivity, exert positive effects but sometimes also negative effects on soil's properties [11].

In the case of the soil parcel fertilized with farmyard manure $\left(a_{1} b_{5}\right)$ for the $0-15 \mathrm{~cm}$ working depth, the lowest manganese content was registered, due to Triticum aestivum's capacity to stabilize metals in soil.

The lowest metal contents in soil (nickel, copper, zinc, arsenic, lead) have been registered for the experimental variant wheat - fertilization with nitrogen and phosphorous - N90P75 kg/ha $\left(a_{1} b_{4}\right)$, both for 0-15 cm and for $15-30 \mathrm{~cm}$ working depths.

Soil's metal contents variations are mainly due to the applied fertilizers sequence (nitrogen, phosphorous, nitrogen and phosphorous, farmyard manure), to Triticum aestivum's capacity to stabilize/assimilate metals in/from soil, as well as to climatic conditions in 2016.

\section{References}

1.SANGAR, K., RIFAT, H., MUHAMMAD, SHAKIR, F., QAISER, H., NOSHEN A.A., Advances in Crop Science and Technology, 6, no. 1, 2017, p. 328. 2.UZOMA, K.C., INOUE, M., ANDRY, H., FUJ IMAKI, H., ZAHOOR, A., NISHIHARA, E., Soil Use and Management, 27, 2011, p. 205.

3.YANG, R., SU, Y., WANG, T., YANG, Q., Journal of Integrative Agriculture, 15, no. 3, 2017, p. 658.

4.IRIMIA, O., NEDEFF, V., PANAINTE LEHADUS, M., TOMOZEI, C., Journal of Engineering Studies and Research, 22, no. 1, 2016, p. 64. 5.DINU, C., UNGUREANU, E.M., VASILE, G.G., KIM, L., IONESCU, I., ENE, C., SIMION, M., Rev. Chim.(Bucharest), 69, no. 1, 2018, p. 14. 6.MASU, S., COJ OCARIU, L., GRECU, E., MORARIU, F., BORDEAN, F.D., HORABLAGA, M., NITA, L., NITA, S., Rev. Chim.(Bucharest), 69, no. 5, 2018, p. 1110.

7.CHITIMUS, A.D., NEDEFF, V., MOSNEGUTU, E.F. PANAINTE M., Environmental Engineering and Management] ournal, 11, no. 12, 2012, p. 2161.

8.TURCU, M., BARSAN, N., IRIMIA, O., JOITA, I., BELCIU, M., Environmental Engineering and Management J ournal, 13, no. 7, 2014, p. 1751.

9.SIFOLO, S.C, JEROME, E.T., KOUADIO, I.K., BARSAN, N., NEDEFF, V., ZORO, I.A., International J ournal of Agronomy and Agricultural Research, 8, no. 3, 2016, p. 26.

10. BELCIU, M.C., MOSNEGUTU, E.F., NEDEFF, V., CHITIMUS, A.D., BARSAN, N., FIORE, S., Environmental Engineering and Management Journal, 15, no. 3, p. 2057.

11.CHITIMUS, A.D., Studies and researches on the influence of mechanical and physical properties of soil in self-cleaning and cleaning, PhD Thesis, Vasile Alecsandri University of Bacau, Romania, 2011.

12.CHITIMUS, A.D., NEDEFF, V., MOSNEGUTU, E., LAZAR, G., Soil Cleaning Techniques (in Romanian), Ed. Alma Mater, Bacau, 2012, p. 51.

13.CHITIMUS, A.D., NEDEFF, V., LAZAR, G., Journal of Engineering Studies and Research, 17, no. 4, 2011, p. 24.

14.CHITIMUS, A.D., RADU, C., NEDEFF, V., MOSNEGUTU, E., BARSAN, N., Scientific Study \& Research Chemistry \& Chemical Engineering, Biotechnology, Food Industry, 17, no. 4, 2016, p. 381.

15.CHITIMUS, A.D., BARSAN, N., NEDEFF, V., MOSNEGUTU, E., MUSCALU (PLESCAN), O., Studies and research concerning the influence of liquid pollutants' leaching speed in the soil on the process of cleaning and self-cleaning, 17th International Multidisciplinary Scientific GeoConference SGEM 2017, 17, no. 51, 2017, pp. 859-866.

16.CLEMENS, S., PALMGREN, M.G., KRAMER, U., Plant Science, 7, 2002, p. 309.

17.GREGER, M., Metal availability, uptake, transport and accumulation in plants, in Heavy Metal Stress in Plants - from biomolecules to ecosystems, Springer Heidelberg, 2004, pp. 1-27. 
18.RADU, C., CHITIMUS, A.D., TURCU, M., ARDELEANU, G., BELCIU, M., Environmental Engineering and Management Journal, 13, no. 7, 2014, p. 1687.

19.RADU, C., NEDEFF, V., CHITIMUS, A.D., Journal of Engineering Studies and Research, 19, no. 2, 2013, p. 89.

20.SENILA, M., LEVEI, E., MICLEAN, M., SENILA, L., STEFANESCU, L., MARGINEAN, S., OZUNU, A., ROMAN, C., Environmental Engineering and Management J ournal, 10, 2011, p. 59.

21.PAPADATU, C.P., BORDEI, M., ROMANESCU, G., SANDU, I., Rev. Chim. (Bucharest), 67, no. 9, 2016, p. 1728.

22. SAMREEN, S., INAM, A., KHAN, A.A., International J ournal of Conservation Science, 8, no. 4, 2017, p. 695.

23. BURTEA, M.C., SANDU, I.G., CIOROMELE, G.A., BORDEI, M., CIUREA, A., ROMANESCU, G., Rev. Chim. (Bucharest), 66, no. 5, 2015, p. 621.
24. DAIRO, O.S., SOYELU, O.J., International J ournal of Conservation Science, 8, no. 3, 2017, p. 509.

25. UNGUREANU, G., IGNAT, G., VINTU, C.R., DIACONU, C.D., SANDU, I.G., Rev. Chim. (Bucharest), 68, no. 3, 2017, p. 570.

26. VASILACHE, V., CRETU, M.A., PASCU, L.F., RISCA, M., CIORNEA, E., MAXIM, C., SANDU, I.G., CIOBANU, C.I., International Journal of Conservation Science, 6, no. 1, 2015, p. 93.

27. *** ICP-MS System, 7500cx ICP-MS, Agilent, Operating Manual, 2007.

28.*** Atomic absorption spectrometry (AAS) ZEEnit 700, Operating Manual, 2009.

29.***SR EN ISO 17294-2:2016 Water quality-Application of inductively coupled plasma mass spectrometry (ICP-MS) - Part 2: Determination of selected elements including uranium isotopes. 30.*** Penetrologger, Operating instructions, 2010.

Manuscript received: 19.02 .2018 